\title{
The impact of Process Quality and Quality Control on Organizational Competitiveness at 5-star hotels in Dubai
}

\author{
Ali Alzoubi \\ Directorate of General Security, JORDAN, alialzoubi@yahoo.com
}

\begin{abstract}
Hotel industry is seeing many challenges because of the market challenges due to perfect competition market. Among these challenges quality assurance and quality control has significant impact because these factors determine the competitiveness level of the organization. In this research study we explained the hotel industry in the light of process quality and quality control. Interview was arranged and data was collected for interpretation. Results stated that process quality and quality control has significant impact on attaining competitiveness in hotel industry. This study can contribute a lot not just in theoretical field but also in practical field where the hotels can evaluate their own performance and the lacking in their own strategies.
\end{abstract}

Keywords: Process control, quality control, organizational competitiveness, hotel industry

\section{Introduction}

Process quality is the degree to which implementation as well as observation is done when it comes to acceptable process with regards to quality's criteria and measurement by an organization for the production of artifacts [1]. In simple words, the process quality actually means or its focus is on the parts of manufacturing process i.e. the efficiency of the process and its effectiveness in order to achieve the required goals and objectives [2]. An example can be used of the temperature control which is being used when a component has to be molded in order to manufacture the final product. This is part of the process and hence if a single part of the process is not controlled or is of inferior quality then it can impact the final good and thus leading to inferior quality final product [3].

Quality control or QC, refers to a process which is being used by a business in order to make sure that quality of the product is improved with time and is also maintained as per the standards of the company or international standards [4]. It is actually a process which through an 
environment is created for employees as well as the management so that they can always look for perfection [5]. This is usually achieved by periodic training for employees, setting high standards of quality, conducting quality tests on the goods manufactured and dispatching only final products to customers which have passed final quality control tests [6].

The quality control process is beneficial for consumers as well because researchers and scholars have devised that this process always increases the satisfaction of customers. Since hotel industry is highly competitiveness, customers prefer quality over prices there and thus they want value against the prices they pay [7]. So for this reason, the quality control process plays a vital control in increasing their satisfaction and thus this comes handy to the hotel as well because it retains its loyal customers who love to visit the place again. The better quality services with the help of quality control is the key in this process [8].

Competitiveness refers to the ability of an organization, an individual or a country etc. to be competitive enough to compete with its rivals in the industry [9]. In terms of an organization, it is directly linked with its performance because if the performance of the company is of high standards and satisfies its customers only then we can say that the organization is a competitive organization [10].

\section{Process Quality}

The operational definition of process quality is the degree to which implementation as well as observation is done when it comes to acceptable process with regards to quality's criteria and measurement by an organization for the production of artifacts [9].

Process quality is the overall procedure utilized by the organizations in order to perform quality system in the organization [11]. The purpose of process quality is to implement such activities which ensures that every process is designed on the philosophy of quality. Since hotel industry is the service sector so maintain quality is a big challenge. Process quality will ensure the competitiveness to the hotel [12]. Process quality is the translation of such approach which is highly systematic and aim to optimize the overall process [10].

\section{Quality Control}

Quality control or QC, refers to a process which is being used by a business in order to make sure that quality of the product is improved with time and is also maintained as per the standards of the company or international standards [13]. In order to be competitive, the quality control processes are done regularly in hotels so that the operational and administrative expenses are controlled. With the help of this, the hotels are able to increase their revenues and profits which in turn place them in a more competitive position in the market against their competitors and thus they are better off. There were different types of research studies carried 
out in different parts of the world regarding the importance of quality control in hotel industry [14].

Quality control is a controlling system which is designed to monitor the process of quality and avoid errors [8]. Under the quality control system, the number of errors always reduced and show zero tolerance. This philosophy ensures that there is no tolerance towards negligence. In the hotel industry quality control is the fundamental principle which enables them to compete effectively [15]. For hotels, goodwill is important because it increases the attraction and influx of customers. With the help of goodwill, the share prices also rise which in turn make the companies more valuable. The quality control processes always raise the goodwill in the minds of consumers and thus they pay more visits to the hotel because of their historic experience [14][2]. This is the reason the hotels are paying more and more attention to quality control processes in order to have more productive operations so that they fight the competition in the market against other new and old rivals. Since the industry is highly volatile, there are new entrants in the market almost every day which in turn increases the competition in the hotel industry [16]. One of the advantages of a rigid competition in the industry is that it increases the quality of the services provided by the companies and thus this is done through quality control measures. The quality control measures are taken at each and every step so that if there are any flaws, they can be removed on the spot otherwise the quality check in the end might be detrimental if the hotels find flaws in their process [17].

\section{Organizational Competitiveness}

Competitiveness refers to the ability of an organization, an individual or a country etc. to be competitive enough to compete with its rivals in the industry [14]. Competitiveness in the industry explains unique characteristics of an organization which differentiates it from others [18]. In the hotel industry achieving competitiveness is a big challenge especially in the region where tourism is very high. Above average performance is possible only when there is a system of process quality and quality control [17].

\section{Literature Review}

[1] evaluated in their research that process quality improves quality control. Hotel industry has seen a rise in its demand since the world has become a global heritage. The reason is that people have been flying more often than before because of business or personal reasons. And thus the demand for hotel industry has risen. For this reason, it's very important for hotels to retain their competitive edges in the market so that they do not lose their customers and retain their loyalty [19]. The quality control process is one of the key reasons why hotels have retained their competitive edge in the market. According to the research studies carried out at 
John Hopkins University, the quality control process makes the employees quality consciousness [20]. This is encouraging because it lets the workers be more productive towards the organization because they focus on quality and since quality is one of the foremost demands of the customers, the hotels retain their competitive edge in the market [10]. This allows them to attract more and more customers because people do not compromise on quality but they can compromise on price. Value for money is important which can only be done through quality control [1].

[11] stated that process quality leads competitiveness. Hotel industry experiences a lot of different administrative and operational expenses. These continuously increase if there is no quality control process. But with the help of quality control, the hotel is able to reduce the prices or at least control them [21]. According to Oxford University, resources are more formally and smoothly utilized when there is quality control in hotels than those where the idea and concept of quality control do not exist. This is because of the reason that maximum efficiency is achieved due to quality control. The wastes are minimized and thus the hotels are more efficient in the market. And for this reason, the quality control has a vital place in hotel industry since long [22].

[4] evaluated that inspection is important in hotels which is done through implementing process quality standards. The inspection costs are high if the inspection process is longer. The inspection team carried out a detailed inspection of the hotel and finds out the flaws and thus the flaws are higher if there are no quality control processes [10]. The economies are achieved with the help of quality control and thus the hotels have to bear a minimum cost in terms of inspection and quality. This is important because it actually derives more profits to the company which in turn places them in a stronger position in the market which is a healthy activity.

[18] evaluated that employees are very important for hotels. For hotels, employees are perhaps the most important assets. For this reason, the morale of employees is very necessary at the workplace. It has been seen through different researches that employees have a high morale if they are working for a company which is focusing on providing quality products and services to the consumers. This is important because this is a psychological factor where employees are comfortable if their companies are providing quality service to the customers in the market [15]. And this is always done with the help of quality control at the workplace. This also increases the relation between employers and employees. The relation is always cordial between the management and workers because quality control provides a friendly and supportive atmosphere where the customers are happy and when the customers are happy, the 
company always prospers. This is the reason that quality control is beneficial for hotels around the globe [23]. Since Europe and North America have a big hotel industry, quality control matters a lot because it's a process which refines the services of the organizations and puts them in a better place in the market. This enhances the employer and employee relations too. Also, hotels are very much dependent on advertisements as well because these advertisements and promotional campaigns play a vital role in attracting customers [8].

For this reason, the quality control processes are important because the quality control processes allow hotels to present them in a much better way than their competitors who have not implemented the quality control process. Customers come to know about the hotel through advertisements and thus they prefer to visit because advertising and promotions play a vital role. The public confidence is always won through effective advertising which is done extensively in the hotel industry [7].

[9] explained that process quality and quality controls work together. The standard quality is maintained and thus the hotel does not have to put fixed prices for its products. The prevalent prices are often adopted by the other hotels too and thus the threat of fixed price is no more in the industry. This is a big advantage of quality control measure especially for the hotel industry [24]. According to researchers in Harvard University, quality control increases sales. The reason is that quality is enhanced because of quality control measures and thus the services are more attractive than before. This helps organizations increase their sales. The same goes for the hotel industry because increase in quality is something which is preferred by customers around the globe and hotel industry is famous for its quality and comfort for its customers. The quality control measures create new demands for the hotel industry which in turn helps the hotels get new prospective clients and thus they see an increase in their sales in the market.

[22] stated that process quality and quality control brings competitiveness. Quality control plays a very important role in the hotel industry. Since the demands are changing, the tastes and preferences of people are also changing and that's why hotels have to fight the competition and stay in the business. For this reason, quality control matters a lot at each stage in order to have a competitive edge and to remain abreast of competition. For these and many other reasons, the advantages of quality control cannot be eliminated because its implementation in the hotel industry is on the boom like in manufacturing industry because the ultimate advantages of both are same i.e. to remain abreast of competition and provide a competitive edge. Because of the nature of the industry, companies (hotels) cannot survive because of the rigid competition [5]. They have to extensively go for marketing and 
promotional campaigns in order to attract people from around the globe. The tourism has played a vital part in booming the hotel industry because tourists are one of the reasons why hotel industry is successful in the market. The prospective customer base in the hotel industry is all because of tourism and business trips. And thus quality control is playing a fundamental role in this regard [21].

\section{UAE Hotels Industry}

United Arab Emirates (UAE) as the second largest economy in the Middle East consists of more than one thousand, 300 of them classified as 5-star and above. The emirate of Dubai is the focal point of the UAE's tourism industry, in terms of numbers of visitors and fabulous infrastructure (Vij and Upadhya, 2020). The country has been ranked sixth in the world for the quality of its infrastructure according to the World Economic Forum (WEF, 2019). UAE, and Dubai particularly has not only successfully diversified from being dominated by the oil industry to development of the tourism sector, but also poses an example of excelling in tourism in the absence of a conducive environment and natural attractions, Hospitality sector being reshaped by disruptions, changing consumer behaviour (Vij and Verma, 2016). The tourism and hospitality sector in Dubai has also grown steeply in the past decade. The hotel business in Dubai covers the ownership and representation of many national and international hotels.

\section{Problem Statement and Research Gap and Contribution}

In the hotel industry being competitive means that the hotel is offering such quality and services which is above the industry standards and customer satisfaction is higher. It is possible only when there is a structured approach towards the implementation of process quality and to run this process the system, should be monitored which is based on quality standards. Therefore; hotel industry is highly influenced by the process quality and quality control to achieve competitiveness. 


\section{Research Model}

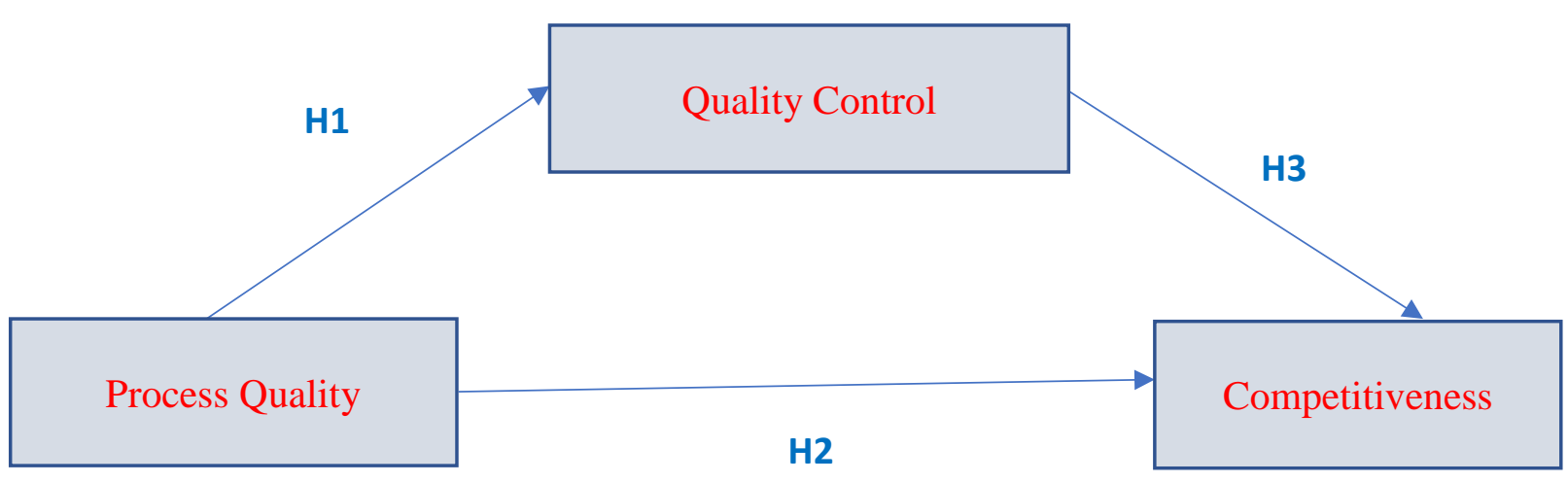

\section{Research Hypotheses}

Ho1: Process Quality has no statistical impact on Quality Control in 5-stars hotels in Dubai at $(\alpha \leq 0.05)$

Ho2: Process Quality has no statistical impact on Organizational Competitiveness in 5-stars hotels in Dubai at $(\alpha \leq 0.05)$ level. level.

Ho3: Quality Control has no statistical impact on Organizational Competitiveness in 5-stars hotels in Dubai at $(\alpha \leq 0.05)$ level.

\section{Methodology and Research Design}

The research falls under the Applied research category since it aims to expand the existing knowledge, and Relativism Ontology Type, Subjectivism (EMIC) Epistemology Type, and Interpretivism Research Philosophy because the research asking the participants to express their perceptions toward the research questions (questionnaire).

The research will follow the quantitative research nature by collecting empirical and numerical data through structured survey then statistical tools will be used to prove the model validation. The methodology nature will follow the deductive analysis approach since we aim to expand the knowledge about the research variables. While the research method will take the Descriptive and Explanatory research design since we aim to investigate the relationship and the impact of Quality Orientation on Achieving a Competitive Advantage: The mediating role of Dynamic Capabilities [25]. On the other hand, the research strategy will be the Correlational/Causal strategy because we attempt to establish cause- effect relationships among the variables. A questionnaire has been designed on a 5-points likert scale to measure the variables and dimensions of the research. 


\section{Population and Sample}

The hotel industry at UAE considered to be the population of this research. The 5-star hotels at Dubai which are (119) hotels have been chosen as the sample of this research. 5-star hotels of Dubai have its own unique characteristics and differentiates on the basis of quality services, premium location and high standard of meeting quality control. The sampling technique was the nonrandom convenient sampling technique. The unit of analysis consisted managers working at the surveyed hotels in Dubai. The survey is the instrumental design. A 259 appropriate questionnaires used for the analysis out of the total number of employees who participated in the survey. Empirical and primary data was collected through questionnaire. Self-administrative questionnaire was utilized for data collection. Questionnaire was distributed to the surveyed employees through email within 3 months' follow-up. The validity of the questionnaire was tested and reliability analysis was done before generalizing the results.

\section{Reliability}

A reliability test is basically a stable and consistent results that can be produced through assessment tool over the time. A study can be measured to be reliable if the its result produced under comparable methodology; which means study tool has the ability to be applicable and repeatable over the time. Hence, this research has used Cronbach's alpha tool, and the minimum reliability score to be accepted is 0.60 . As shown in below table 1 , the reliability tool has been tested two variables (dependent and independent factors), and each variable and its dimensions through the measurement instrument. The reliability scores for quality control, process quality, and competitiveness and its dimensions showed strongly significant, where Cronbach's alpha value were above (0.60) for all variables, which indicates that the items are internally consistent for each dimension.

Table 1 Cronbach's Alpha Coefficient for Study variables

\begin{tabular}{lc}
\hline Construct & Cronbach's Alpha \\
\hline Process quality & 0.698 \\
Quality control & 0.751 \\
Competitiveness & 0.802 \\
\hline
\end{tabular}

\section{Data Analysis}

The questionnaire of the study which was distributed to 22 different bank branches in Fujairah, has been given to a number of academic and industrial experts to review, then all 
comments have been take into serious consideration and adapted before it distributed. All received questionnaires were checked for validity. A 220 valid Questionnaire and the data were investigated and examined through statistical and analytical package (SPSS), in order to test the relationship and the impact of Information System Capabilities, Quality control on Competitiveness, descriptive statistic, correlation and regression analysis and ANOVA analysis were conducted to obtain the results [19].

\section{Descriptive Analysis}

Descriptive analysis and statistic are a way used on studying of data and responsiveness of respondents about research variables that help in describing and summarizing the information into a meaningful. As showed in Table 2 the importance for each construct of the study indicating significant value, as all means and standard deviation refer to accepted values.

Table 2 Descriptive Statistics for Study variables

\begin{tabular}{lccc}
\hline Construct & Mean & Std. Deviation & Variance \\
\hline Process quality & 3.571 & .91834 & .708 \\
Quality control & 3.652 & .86632 & .846 \\
Competitiveness & 3.479 & .79841 & .912 \\
\hline
\end{tabular}

\section{Hypotheses Testing}

Table 3 illustrate the results of Correlation, ANOVA and Regression analysis to quality control in Process quality, it described significant relationship between competitiveness in Process quality where the correlation $(r)$ is $(0.591)$. The determinant coefficient is $(0.349)$ which means that $(0.349)$ changeability in the quality control is explained by the changeability in process quality.

Table 3Correlation, ANOVA and Regression analysis to Quality control in Process quality

\begin{tabular}{|c|c|c|c|c|c|c|c|c|c|}
\hline & $\bar{r}$ & $\mathrm{r}^{2}$ & $\mathrm{~F}$ & $\mathrm{DF}$ & Sig* & $\beta$ & & $t$ & Sig* \\
\hline $\begin{array}{l}\text { Quality } \\
\text { control }\end{array}$ & .591 & .349 & $\begin{array}{c}19 . \\
138\end{array}$ & $\begin{array}{c}1 \\
258 \\
259\end{array}$ & .000 & Process quality & 0.318 & 2.201 & 0.002 \\
\hline
\end{tabular}

$*$ level of significance $(\alpha \leq 0.05) * *$ Critical $t(d f / p)=1.64$

ANOVA analysis results indicate that there is impact of process quality on quality control at beta is $(0.318)$ confirmed by $(t)$ is (2.201) and (f) is (19.138) and all values are significant at $(\alpha \leq 0.05)$ level. This evidence supports the first hypothesis which prove the impact of process quality on quality control.

Table 4 illustrate the results of Correlation, ANOVA and Regression analysis to competitiveness in process quality, it described significant relationship between competitiveness in process quality where the correlation $(r)$ is $(0.518)$. The determinant coefficient is $(0.268)$ which means that $(0.268)$ changeability in the competitiveness is explained by the changeability in process quality.

Table 4Correlation, ANOVA and Regression analysis to competitiveness in Process quality

\begin{tabular}{|c|c|c|c|c|c|c|c|c|c|}
\hline & $\mathrm{r}$ & $\mathrm{r}^{2}$ & $\mathrm{~F}$ & DF & Sig* & $\beta$ & & $\mathrm{t}$ & Sig* \\
\hline $\begin{array}{c}\text { Competitiv } \\
\text { eness }\end{array}$ & .518 & .268 & & $\begin{array}{c}1 \\
258 \\
\end{array}$ & .000 & Process quality & 0.298 & 2.971 & 0.001 \\
\hline
\end{tabular}


\begin{tabular}{c}
10. \\
$783 \quad 259$ \\
\hline$*$ level of significance $(\alpha \leq 0.05) * *$ Critical $\mathrm{t}(\mathrm{df} / \mathrm{p})=1.64$
\end{tabular}

ANOVA analysis results indicate that there is impact of process quality on competitiveness at beta is $(0.298)$ confirmed by $(t)$ is (2.971) and (f) is (10.783) and all values are significant at $(\alpha \leq 0.05)$ level. This evidence supports the second hypothesis which prove the impact of process quality on competitiveness.

Table 5 illustrate the results of Correlation, ANOVA and Regression analysis to competitiveness in Quality control, it described significant relationship between competitiveness in Process quality and Quality control where the correlation (r) is (0.509). The determinant coefficient is (0.259) which means that $(0.259)$ changeability in the competitiveness is explained by the changeability in quality control.

Table 5Correlation, ANOVA and Regression analysis to competitiveness in Quality control

\begin{tabular}{|c|c|c|c|c|c|c|c|c|c|}
\hline & $\mathrm{r}$ & $\mathrm{r}^{2}$ & $\mathrm{~F}$ & DF & Sig* & $\beta$ & & $t$ & Sig* \\
\hline $\begin{array}{l}\text { Competitiv } \\
\text { eness }\end{array}$ & .509 & .259 & $\begin{array}{l}22 . \\
326\end{array}$ & $\frac{1}{258}$ & .000 & Quality control & 0.413 & 3.156 & 0.001 \\
\hline
\end{tabular}

$*$ level of significance $(\alpha \leq 0.05) * *$ Critical $t(d f / p)=1.64$

ANOVA analysis results indicate that there is impact of quality control on competitiveness at beta is $(0.413)$ confirmed by $(t)$ is (3.156) and (f) is (22.326) and all values are significant at $(\alpha \leq 0.05)$ level. This evidence supports the third hypothesis which prove the impact of quality control on competitiveness. 


\section{Discussion of the Results}

In this section, the collected data through the questionnaire is analyzed and the results of data were interpreted. The results showed the analysis of process quality of the 5-stars hotels in Dubai, their quality services and their organizational competitiveness.

The results showed that process quality of the 5-stars hotels in Dubai lead to more quality control, coefficient of determination (0.349) correlation coefficient (0.591), ANOVA results $(\mathrm{t}=2.201)$ and regression results $(\mathrm{f}=19.138)$ are significant at $(\alpha \leq 0.05)$, all prove the first alternative hypothesis which stated that Process Quality has statistical impact on Quality Control in 5-stars hotels in Dubai at $(\alpha \leq 0.05)$.

Whereas the results refers that process quality of the 5-stars hotels in Dubai lead to organizational competitiveness, coefficient of determination (0.268) correlation coefficient (0.518), ANOVA results $(\mathrm{t}=2.971)$ and regression results $(\mathrm{f}=10.783)$ are significant at $(\alpha \leq 0.05)$, all prove the first alternative hypothesis which stated that Process Quality has no statistical impact on Organizational Competitiveness in 5-stars hotels in Dubai at $(\alpha \leq 0.05)$.

Moreover, The results indicated that quality control of the 5-stars hotels in Dubai lead to organizational competitiveness, coefficient of determination (0.259) correlation coefficient (0.509), ANOVA results $(\mathrm{t}=3.156)$ and regression results $(\mathrm{f}=22.326)$ are significant at $(\alpha \leq 0.05)$, all prove the first alternative hypothesis which stated that Quality Control has no statistical impact on Organizational Competitiveness in 5-stars hotels in Dubai at $(\alpha \leq 0.05)$.

However, a few years back things were not the same for them because most hotels did not have had the competitive edge before over its competitors which it enjoys today. The became possible once they applied process quality and quality control in their operations. The application of process quality helped the hotels to find out where they are lacking and what was their weakness. Some hotels did not have required amount of control on its staff when it came to serving customers and therefore after applying the process quality and quality control it was able to tackle this issue. Staff members were given better training to improve the overall process quality which resulted in better quality control over its services and thus, improved services to customers which increased the competitiveness of the 5-stars hotels in Dubai in the UAE hotel industry. 


\section{Conclusion}

Improvement is an ongoing process and therefore 5-stars hotels in Dubai should keep working on this by providing regular training to its staff members. Regular feedback should also be taken from its guests in order to find out their experience at the hotel so that competitiveness level can be evaluated on regular basis. The results show that the hotel industry needs to fix their quality standards and make sure it never goes down in any case. But then again it is also necessary to improve day by day with new strategies and policies that would help the hospitality experience of the guests better and best. Knowing that no hotel is alone in the race but there are thousands of other competitions standing and waiting to take the place of top [4].

\section{Theoretical and Practical Implications}

This study contributes a lot in the field of learning for academics in the field of hospitality and how the industry works and makes everyday a try of improvement. The hotel industry is suffering not because of lack of profitability by customers but because of the fact of inconsistency where a customer is unable to receive the same standard of services every single time. This is where the quality assurance comes in. The results in this study support the evidence that hotels not only need to standardize their quality but also improve it and in no way can let it down. 


\section{References}

[1] F. Oltean and M. Gabor, "QUALITY MANAGEMENT AND FIRM PERFORMANCE IN THE HOTEL INDUSTRY: EVIDENCE FROM MURES COUNTY," in North International Conference on Economics, 2016, pp. 100-108.

[2] H. Alzoubi, M. Alshurideh, B. Al Kurdi, and M. Inairat, "Do perceived service value, quality, price fairness and service recovery shape customer satisfaction and delight? A practical study in the service telecommunication context," Uncertain Supply Chain Manag., vol. 8, no. 3, pp. 579-588, 2020, doi: 10.5267/j.uscm.2020.2.005.

[3] N. Alnzar, M. Alnuami, and H. Alzoubi, "Analyzing the Appropriate Cognitive Styles and its effect on Strategic Innovation in Jordanian Universities., Int. J. Bus. Excell., vol. 13, no. 1, pp. 127-140, 2017, [Online]. Available: https://www.inderscienceonline.com/doi/abs/10.1504/IJBEX.2017.085799.

[4] H. Madanat and M. T. Nuseir, "The use of integrated management approaches and their impact on customers' satisfaction and business success," Int. J. Bus. Excell., vol. 11, no. 1, p. 120, 2017, doi: 10.1504/ijbex.2017.10000687.

[5] M. Alshurideh, A. Gasaymeh, G. Ahmed, H. Alzoubi, and B. Al Kurd, "Loyalty program effectiveness: Theoretical reviews and practical proofs," Uncertain Supply Chain Manag., vol. 8, no. 3, pp. 599-612, 2020, doi: 10.5267/j.uscm.2020.2.003.

[6] M. Alnuami, H. Alzoubi, D. Ajelat, and A. Alzoubi, “Toward Intelligent Organizations: An Empirical investigation of Learning Orientation's role in Technical Innovation,” Int. J. Innov. Learn., vol. 29, no. 2, pp. 207-221, 2021, [Online]. Available: https://www.inderscienceonline.com/doi/abs/10.1504/IJIL.2021.112996.

[7] H. M. Alzoubi and R. Yanamandra, "Investigating the mediating role of information sharing strategy on agile supply chain," Uncertain Supply Chain Manag., vol. 8, no. 2, pp. 273-284, 2020, doi: 10.5267/j.uscm.2019.12.004.

[8] L. A. Kasiri, K. T. Guan Cheng, M. Sambasivan, and S. M. Sidin, "Integration of standardization and customization: Impact on service quality, customer satisfaction, and loyalty,” J. Retail. Consum. Serv., vol. 35, no. November 2016, pp. 91-97, 2017, doi: 10.1016/j.jretconser.2016.11.007.

[9] A. Serra-Cantallops, D. D. Peña-Miranda, J. Ramón-Cardona, and O. Martorell-Cunill, "Progress in Research on CSR and the Hotel Industry (2006-2015)*," Cornell Hosp. Q., vol. 59, no. 1, pp. 15-38, 2018, doi: 10.1177/1938965517719267.

[10] H. Alzoubi and G. Ahmed, "Do TQM practices improve organisational success? A case study of electronics industry in the UAE," Int. J. Econ. Bus. Res., vol. 17, no. 4, 
pp. 459-472, 2019, doi: 10.1504/IJEBR.2019.099975.

[11] H. Semuel, H. Siagian, and S. Octavia, "The Effect of Leadership and Innovation on Differentiation Strategy and Company Performance," Procedia - Soc. Behav. Sci., vol. 237, no. June 2016, pp. 1152-1159, 2017, doi: 10.1016/j.sbspro.2017.02.171.

[12] B. Al Kurdi, H. Elrehail, and H. M. Alzoubi, “THE INTERPLAY AMONG HRM PRACTICES , JOB SATISFACTION AND INTENTION TO LEAVE : AN EMPIRICAL INVESTIGATION,” no. August, 2021.

[13] M. F. Shamsudin, S. A. Esa, and A. M. Ali, "Determinants of customer loyalty towards the hotel industry in Malaysia,” Int. J. Innov. Creat. Chang., vol. 6, no. 9, pp. 21-29, 2019.

[14] Y. H. Akbar and A. Tracogna, "The sharing economy and the future of the hotel industry: Transaction cost theory and platform economics," Int. J. Hosp. Manag., vol. 71, no. December 2017, pp. 91-101, 2018, doi: 10.1016/j.ijhm.2017.12.004.

[15] H. M. Alzoubi, G. Ahmed, A. Al-Gasaymeh, and B. Al Kurdi, "Empirical study on sustainable supply chain strategies and its impact on competitive priorities: The mediating role of supply chain collaboration,” Manag. Sci. Lett., vol. 10, no. 3, pp. 703-708, 2020, doi: 10.5267/j.ms1.2019.9.008.

[16] H. M. Alzoubi and R. Aziz, "Does emotional intelligence contribute to quality of strategic decisions? The mediating role of open innovation,” J. Open Innov. Technol. Mark. Complex., vol. 7, no. 2, 2021, doi: 10.3390/joitmc7020130.

[17] S. Joghee, H. M. Alzoubi, and A. R. Dubey, "Decisions effectiveness of FDI investment biases at real estate industry: Empirical evidence from Dubai smart city projects,” Int. J. Sci. Technol. Res., vol. 9, no. 3, pp. 3499-3503, 2020.

[18] S. Mansour and D. Mohanna, "Mediating role of job stress between work-family conflict, work-leisure conflict, and employees' perception of service quality in the hotel industry in France,” J. Hum. Resour. Hosp. Tour., vol. 17, no. 2, pp. 154-174, 2018, doi: 10.1080/15332845.2017.1340755.

[19] A. Q. M. Alhamad, I. Akour, M. Alshurideh, A. Q. Al-Hamad, B. Al Kurdi, and H. Alzoubi, "Predicting the intention to use google glass: A comparative approach using machine learning models and PLS-SEM,” Int. J. Data Netw. Sci., vol. 5, no. 3, pp. 311-320, 2021, doi: 10.5267/j.ijdns.2021.6.002.

[20] T. M. Ghazal et al., "IoT for Smart Cities: Machine Learning Approaches in Smart Healthcare-A Review," Futur. Internet, vol. 13, no. 8, p. 218, 2021, doi: 10.3390/fi13080218. 
[21] S. Hamadneh, O. Pederson, M. Alshurideh, B. Al Kurdi, and H. Alzoubi, “AN INVESTIGATION OF THE ROLE OF SUPPLY CHAIN VISIBILITY INTO THE AN INVESTIGATION OF THE ROLE OF SUPPLY CHAIN VISIBILITY INTO THE SCOTTISH BLOOD,” no. September, 2021.

[22] Y. He, C. Gu, Z. He, and J. Cui, "Reliability-oriented quality control approach for production process based on RQR chain,” Total Qual. Manag. Bus. Excell., vol. 29, no. 5-6, pp. 652-672, 2018, doi: 10.1080/14783363.2016.1224086.

[23] M. A. Alnuaimi, H. M. Alzoubi, and N. N. Alnazer, "Analysing the appropriate cognitive styles and its effect on strategic innovation in Jordanian universities,” Int. J. Bus. Excell., vol. 13, no. 1, p. 127, 2017, doi: 10.1504/ijbex.2017.10006235.

[24] A. Vargas-Sánchez et al., "Editorial Team Editor in Chief Editorial Board Advisory Board (Spanish Members) Advisory Board (Other European Members) Advisory Board (Members from the rest of the world)."

[25] S. K. Yeng, “( Tqm ) on Competitive Advantage : a Conceptual Mixed Method Study in the," vol. 17, no. 2, pp. 1-9, 2018.

[26] Ghazal, T. M., Noreen, S., Said, R. A., Khan, M. A., Siddiqui, S. Y. et al. (2022). Energy Demand Forecasting Using Fused Machine Learning Approaches. Intelligent Automation \& Soft Computing, 31(1), 539-553.

[27] Ghazal, T.M. Internet of Things with Artificial Intelligence for Health Care Security. Arab J Sci Eng (2021). https://doi.org/10.1007/s13369-021-06083-8

[28] Aslam, M. S., Ghazal, T. M., Fatima, A., Said, R. A., Abbas, S. et al. (2021). EnergyEfficiency Model for Residential Buildings Using Supervised Machine Learning Algorithm. Intelligent Automation \& Soft Computing, 30(3), 881-888.

[29] Ghazal, T. M., Hussain, M. Z., Said, R. A., Nadeem, A., Hasan, M. K. et al. (2021). Performances of K-Means Clustering Algorithm with Different Distance Metrics. Intelligent Automation \& Soft Computing, 30(2), 735-742.

[30] Khan, Q., Ghazal, T. M., Abbas, S., Khan, W. A., Khan, M. A. et al. (2021). Modeling Habit Patterns Using Conditional Reflexes in Agency. Intelligent Automation \& Soft Computing, 30(2), 539-552.

[31] Rehman, E., Khan, M. A., Soomro, T. R., Taleb, N., Afifi, M. A., \& Ghazal, T. M. (2021). Using Blockchain to Ensure Trust between Donor Agencies and NGOs in Under-Developed Countries. Computers, 10(8), 98. doi:10.3390/computers10080098 [32] Ghazal, T.M. Positioning of UAV Base Stations Using 5G and Beyond Networks for IoMT Applications. Arab J Sci Eng (2021). https://doi.org/10.1007/s13369-021- 
05985-X

[33] Ghazal, T.M., Said, R.A. \& Taleb, N. Internet of vehicles and autonomous systems with AI for medical things. Soft Comput (2021). https://doi.org/10.1007/s00500-02106035-2

[34] Matloob, Faseeha \& Ghazal, Taher \& Taleb, Nasser \& Aftab, Shabib \& Ahmad, Munir \& Khan, Muhammad \& Abbas, Sagheer \& Soomro, Tariq. (2021). Software Defect Prediction Using Ensemble Learning: A Systematic Literature Review. IEEE Access. 9. 98754-98771. 10.1109/ACCESS.2021.3095559.

[35] T. M. Ghazal, M. Anam, M. K. Hasan, M. Hussain, M. S. Farooq et al., "Hep-pred: hepatitis c staging prediction using fine gaussian svm," Computers, Materials \& Continua, vol. 69, no.1, pp. 191-203, 2021.

[36] Ghazal, T. M., Kalra, D., \& Afifi, M. A. (2021). The Impact of Deploying the Internet of Things and How Will It Change Our Lives. Solid State Technology, 64(2).

[37] Taher M. Ghazal, Mohammed Kamrul Hasan, Rosilah Hasan, Shayla Islam, Siti Norul Huda Sheikh Abdullah, Mohammed A.M. Afifi, \& Deepak Karla. (2020). Security Vulnerabilities, Attachs, Threats and the Proposed Countermeasures for the Internet of Things Applications Solid State Technology, 63(1), 1566-1574. 